\title{
Racial and Ethnic Health Disparities and the Affordable Care Act: a Status Update
}

\author{
Shawnita Sealy-Jefferson $^{1} \cdot$ Jasmine Vickers $^{1} \cdot$ Angela Elam $^{2} \cdot$ M. Roy Wilson ${ }^{3}$
}

Received: 27 January 2015 /Revised: 9 March 2015 / Accepted: 6 April 2015 / Published online: 3 July 2015

(C) W. Montague Cobb-NMA Health Institute 2015

\begin{abstract}
Persistent racial and ethnic health disparities exist in the USA, despite decades of research and public health initiatives. Several factors contribute to health disparities, including (but not limited to) implicit provider bias, access to health care, social determinants, and biological factors. Disparities in health by race/ethnicity are unacceptable and correctable. The Patient Protection and Affordable Care Act is a comprehensive legislation that is focused on improving health care access, quality, and cost control. This health care reform includes specific provisions which focus on preventive care, the standardized collection of data on race, ethnicity, primary language and disability status, and health information technology. Although some provisions of the Patient Protection and Affordable Care Act have not been implemented, such as funding for the U.S. Public Health Sciences track, which would have addressed the shortage of medical professionals in the USA who are trained to use patient-centered, interdisciplinary, and care coordination approaches, this legislation is still poised to make great strides toward eliminating health disparities. The purpose of this manuscript is to highlight the unprecedented opportunities that exist for the Patient
\end{abstract}

Shawnita Sealy-Jefferson ssealyj@med.wayne.edu

1 Department of Family Medicine and Public Health Sciences, Wayne State University School of Medicine, 3939 Woodward Avenue, Detroit, MI 48201, USA

2 Department of Ophthalmology and Visual Sciences, W. K. Kellogg Eye Center, University of Michigan, 1000 Wall Street, Ann Arbor, MI 48105, USA

3 Office of the President, Wayne State University, 656 W. Kirby, 4200 Faculty/Administration Building, Detroit, MI 48202, USA
Protection and Affordable Care Act to reduce racial and ethnic disparities in health in the USA.

Keywords Health reform · Health disparities · Race/ ethnicity $\cdot$ Affordable care act $\cdot$ Health policy

\section{Introduction}

Despite decades of effort, health disparities in the USA have been particularly resistant to intervention. Many groups of people, particularly under-represented minority populations, are disproportionately burdened by chronic diseases, shortened life expectancy, infant mortality, and other negative health indicators. These populations typically also lack or have insufficient medical insurance coverage [1]. The Patient Protection and Affordable Care Act (ACA) has specific provisions that are aimed at eliminating disparities by improving health care access and quality and by more accurately tracking health disparities [2]. By standardizing the collection of race, ethnicity, language, disability, and geographic data, more meaningful data will be available to perform targeted, culturally competent interventions to improve quality and reduce costs, thereby decreasing racial/ethnic and other health disparities [3]. In this manuscript, we define health disparities, provide background information on the ACA, and describe how it is poised to decrease racial and ethnic health disparities in the USA.

\section{Definition and Early History}

The term "health disparities" has been defined in various ways. The U.S. Department of Health and Human Services assembled the "Secretary's Advisory Committee on National 
Health Promotion and Disease Prevention," which developed objectives for the year 2020 and defined health disparities as "specific types of health differences that are closely linked with social, economic and/or environmental disadvantage" [4]. Efforts to tackle health disparities in the USA, particularly among African Americans, have roots that extend beyond the previous century, with health care professionals, clubwomen, social researchers, and educationalists recognizing differences in well-being and disease outcomes in their communities [5]. In the mid-1980s, the Secretary of the U.S. Department of Health and Human Services reported on the overall health of minority populations, in what has been called the "Heckler Report" [6]. Stark disparities were identified for several minority populations, compared to Whites [6]. In fact, it was reported that 60,000 excess deaths per year among minorities could have been avoided had they been white [6].

Healthy People, a wide-ranging agenda for improving the health of the citizens of the USA, began in 1979, and has been updated every decade [7]. In 2010, Healthy People had two predominant goals: (1) improve the length and quality of life and (2) eliminate health disparities [8]. Nominal progress has been made in meeting these goals, with the goal of eliminating health disparities proving to be particularly elusive [9].

\section{Factors that Contribute to Health Disparities}

Several factors contribute to health disparities, including (but not limited to) implicit provider bias, access to health care, social determinants, and biological factors. Historically, health care practitioners attributed the poor health outcomes of racial/ ethnic minorities to factors outside of physicians' control. However, the Institute of Medicine report, "Unequal Treatment," provided substantial evidence that racial disparities in health are attributed, in part, to physician bias [10]. In regard to access, greater than $50 \%$ of the uninsured population of the USA is comprised of racial/ethnic minority groups [11, 12]. The Institute of Medicine reported that 18,000 lives are prematurely lost each year, due to lack of medical insurance [10].

Having access to health care, however, does not guarantee high-quality care. Minority patients often receive inferior care from under-resourced facilities and over-stretched providers $[13,14]$. It has been shown that race and ethnicity are major determining factors for receipt of high-quality health care, while socioeconomic status, insurance, or disease severity play a lesser role [10]. Over the past decade, increasing attention has been placed on social determinants of health as major contributors of health disparities. Where people live, work, and play determines the "lived experience" of population groups and influences both the biology of disease and health outcomes [7].

\section{The Patient Protection and Affordable Care Act}

The ACA is a comprehensive law, which is focused on health care access, quality, and cost control [15]. This legislation seeks to strengthen the public health infrastructure by shifting the U.S. financing system from fee-for-service compensation, which incentivizes medical providers to increase volume, to a payment model that rewards providers for increasing quality, efficiency, and health outcomes of patients [16]. The health care reform also motivated the Department of Health and $\mathrm{Hu}-$ man Services to unveil an Action Plan to Reduce Health Disparities, with a vision to attain "a nation free of disparities in health and healthcare" [2].

\section{Health Care Access}

Under-represented minorities will encompass $48 \%$ of the 32 million newly insured individuals as a result of the ACA [17]. Individuals living at or below $138 \%$ of the poverty level will be eligible for Medicaid, a federal insurance which was designed to reduce the high uninsured rates of adults. The law will prohibit insurance companies from denying coverage to individuals with pre-existing conditions, a designation that overwhelmingly applies to under-represented minorities [18] (Section 2704). Further, higher premiums can no longer be given to individuals based on gender or race/ethnicity [18] (Section 2701).

The ACA also provides individuals with improved access to clinical preventive services with reduced cost sharing by the beneficiary (i.e., individuals will be provided with a waiver for all or part of the costs for deductibles, copayments, coinsurance, or similar charges for qualified medical expenses) [18] (Section 1402). This health care reform will create a marketplace for health insurance, such that consumers who are ineligible for Medicaid or employer sponsored health insurance are allowed to choose their health coverage. To ensure affordability of coverage, assistance with monthly health insurance premiums will also be available for individuals with income up to $400 \%$ of the federal poverty level [18] (Section 2701).

Unfortunately, because individual states have the authority to opt-out of implementation, the expansion of Medicaid is not consistent across the USA. Currently, 27 states, as well as the District of Columbia, have expanded their Medicaid program, while 23 states have not. If the Medicaid expansion was implemented in all 50 states, it would extend health insurance coverage to approximately 14 million additional people. The expansion was designed to eliminate categorical eligibility for Medicaid thereby decreasing the number of uninsured men and adults without dependent children. In states that do not expand Medicaid, many low-income adults will fall into the "coverage gap," meaning those individuals with incomes above the Medicaid eligibility boundaries but below the lower 
limit to receive tax credits for marketplace insurance premiums would remain uninsured [19].

\section{Focus on Preventive Care}

The ACA also has provisions for a national coordinated prevention strategy to emphasize health promotion and disease prevention [16]. The ACA promotes access to a standard source of adequate and suitable health care [18] (Section 3502). Specifically, it provides increased funding for community health centers which provide comprehensive services at one location, also known as a "patient-centered medical home," for Medicaid recipients with chronic conditions [15].

Another provision of the ACA includes expanded access to clinical preventive benefits for medically underserved children and adolescents by establishing school-based health centers (Section 4101) [18, 20]. Americans only utilize about half of the recommended preventive services, which emphasizes the need for expanded health promotion efforts [21]. These provisions strengthen the fundamental role of communities in health promotion and prevention, especially among minority populations.

The establishment of accountable care organizations is a component of the ACA that could greatly reduce health disparities [18] (Section 3022) [3]. Here, groups of doctors, hospitals, and other health practitioners willingly come together to deliver coordinated care to patients [22]. Under health care reform, incentives are available for organizations to provide cost-effective organized care to patients, which would reduce duplication and disintegration of services [3]. Health care providers are jointly accountable for reaching goals regarding quality improvements and cost containment [3].

\section{Data to Monitor Disparities}

In the USA, a lack of valid and reliable standards for the collection of data to categorize racial/ethnic minority groups has hindered uniform reporting and tracking of health disparities [23]. The ACA requires all federally funded health programs to collect data on race, ethnicity, primary language, and disability status [18] (Section 3101). To ensure the success of integrating quality improvement and disparity elimination efforts, such as targeting interventions and monitoring long-term progress, meaningful performance measures must be stratified by race and ethnicity, language, and disability [24, 25].

\section{Health Care Quality}

Evidence suggests that quality improvements will help to reduce disparities [26-28]. The ACA established a national strategy and priorities to improve health care quality, which includes prioritization of the development of quality measures [18] (Section 3101). Health care providers must report quality measures or face financial penalties. However, these provisions are not without potential problems. For instance, it is possible for some performance measurement incentive programs to create burdens for practitioners who care for highrisk patients. Incentives for reporting data on quality to the public could motivate providers to select patients with more favorable characteristics [29]. They could also unintentionally penalize physicians with considerable minority patient populations, who would likely have poor health outcomes $[25$, 30-33]. Given that racial and ethnic minorities are often served by urban safety-net hospitals and other providers with insufficient resources [13, 14], they may not reap the expected benefits from such quality improvement efforts. Because of the complex needs of their patient populations, the degree to which some providers need more resources, including consideration of case-mix-adjusted payments or those adjusted by patient socioeconomic characteristics, needs to be explored [31].

\section{Health Information Technology}

"Health information technology" refers to a collection of technologies such as electronic health records, electronic clinical decision support tools and clinical documentation, personal health records, technology chronic disease management, and population health and data warehouse tools [34]. Health information technology (HIT) has recently been lauded as a means to improve health care quality and delivery and may be important in addressing health disparities [35, 36]. However, few studies have investigated HIT interventions on health care equity [37].

Health disparities may be impacted by HIT through any of the following mechanisms: (1) patient experiences, (2) execution of microsystems of care (including specific health care providers and care teams), (3) the operation of health care organizations, and/or (4) procedures of the health care environment (including payment and regulation) [38, 39]. Provider-directed HIT-supported quality improvement efforts, such as clinical decision assistance and provider feedback, have been linked with improvements in quality in terms of adherence to guidelines [40, 41]. Such a finding suggests that HIT can have positive impacts on health care disparities by facilitating change at the microsystems level. However, in order to achieve significant improvements in health care equity, especially with respect to important measures of disease control, strategies such as improving patient engagement $[42,43]$, patient-physician communication [44, 45], access to care [36, 46], and system-oriented strategies to improve health care delivery are required. Since implicit bias and other institutional barriers to quality care for 
minority patients may not be apparent to providers [47], HIT may be a promising way to minimize the influence of such non-clinical factors that contribute to sub-optimal clinical decision making, and the ACA provides standards and protocols for collecting such data [18] (Section 1561).

\section{ACA Implementation and Progress to Date}

The ACA has both discretionary and mandatory federal spending features. For the former, during the annual budget process, Congress may or may not appropriate the full amount authorized for any given program. As a result, some programs may receive less funding than was initially approved in the legislation [48]. On the other hand, many of the programs in the ACA legislation are funded through mandatory spending and are not subject to Congressional sanctions.

The ACA has received increased funding every fiscal year since the legislation was implemented in 2010, with an overall total budget of roughly $\$ 15$ billion [48]. The funding priorities have also changed over time, with the majority of spending in 2010 going to programs to improve the health care workforce, whereas nearly $60 \%$ of the total budget in 2013 funded programs aimed at market reform and health centers [48]. Since the ACA was signed into law, the amount of funding received by state agencies has increased annually. These types of organizations have received nearly $50 \%$ of the total ACA funding, of which nearly $40 \%$ has been used for health and communitybased organizations in support of expanding services and facility improvements [48]. Also noteworthy is the elevation of the National Center on Minority Health and Health Disparities at the National Institutes of Health from a Center to a full Institute, which gives it greater authority to design, manage, and assess health disparities research.

\section{ACA Provisions not yet Funded/Otherwise not Implemented}

Several modifications to the spending provisions have occurred since the ACA became law. The changes that had the largest impact were caused by the Budget Control Act of 2011 and the resulting confiscation of budgetary resources in an effort to reduce the deficit over the next 10 years [48]. The sequester decreased federal spending by over $\$ 1$ trillion, but did not affect the following: Medicaid expansion, Children's Health Insurance Program, premium tax credits, or mandatory spending for programs financed with multi-year appropriations. Also, community health centers can only be sequestered at $2 \%$ [48].
On the other hand, all discretionary spending and costsharing reduction grants are subject to the complete sequestration [48]. Specifically, the Middle Class Tax Relief and Job Creation Act of 2012 resulted in a nearly $\$ 6.3$ billion decrease in financial support for the Prevention and Public Health Fund from 2013 to 2021 [48]. Further, the American Taxpayer Relief Act of 2012 caused the withdrawal of $90 \%$ of the discretionary funds for the Consumer Operated and Oriented Plan insurance program. This program was to support the creation of qualified non-profit health coverage issuers for individuals and small businesses $[18,49]$. Funds for the U.S. Public Health Sciences track were also rescinded. This program would have addressed the shortage of medical, dental, physician assistant, pharmacy, behavioral and mental health, public health, and nursing graduates in the USA who are trained to use patient-centered, interdisciplinary, and care coordination approaches during their clinical practice.

\section{Summary Remarks}

Few would disagree with having a society where all persons have an opportunity to enjoy an equally healthy and equally long life. The moral imperative is compelling, but it is not the only reason to eliminate health disparities. Annually, it is estimated that health disparities cost the U.S. economy $\$ 390$ billion [50]. Despite a growing consensus on the importance of eliminating health disparities, how to do so is not as clearcut.

The full implementation of the Affordable Care Act has been thwarted which will undoubtedly slow the progress toward achieving the goal of eliminating health disparities. As of the date of submission of this manuscript $(9$ March 2015), the pending ruling by the Supreme Court, in the case of King $v$ Burwell, will either advance the goals of eliminating health disparities in our country or make achieving them virtually impossible. The case revolves around the legality of the tax credits given to individuals who purchased health insurance through federal marketplaces. These tax credits essentially made comprehensive health care affordable for millions of Americans. If these tax credits are rescinded, the capacity of the health reform to ensure affordable insurance is available to all Americans will be greatly diminished. Yet, there is still cause for optimism in moving forward. We need empirical evidence to support addressing disparities as a way to improve health care quality [51]; the improved data collection efforts to be implemented by the ACA will support this goal. Several additional provisions of the health reform, including improving access to care, quality improvements, and the focus on preventive care, have the potential to positively impact health disparities. It was recently reported that 100,000 lives are lost each year because of 
inadequate health care services [52], and the ACA should make great strides in reducing this number. We now have an unprecedented opportunity to overcome several historical challenges to eliminating racial disparities in health.

Compliance with Ethical Standards Author SSJ, Author JV, Author $\mathrm{AE}$, and Author MRW declare that they have no conflict of interest.

This article does not contain any studies with human participants or animals performed by any of the authors.

Funding Source NIH grant no. F32-HD080338

\section{References}

1. Robert Wood Johnson Foundation. How does the affordable care Act address racial and ethnic disparities in health care? Issue Brief: Health Policy Snapshot, 2011.

2. Office of the Assistant Secretary for Health. HHS action plan to reduce racial and ethnic health disparities: a nation free of disparities in health and health care, HHS, Editor 2011, Office of the Assistant Secretary for Health: Washington, DC

3. Betancourt JR, Corbett J, Bondaryk MR. Addressing disparities and achieving equity: cultural competence, ethics, and health-care transformation. Chest. 2014;145(1):143-8.

4. U.S. Department of Health and Human Services. The Secretary's Advisory Committee on National Health Promotion and Disease Prevention Objectives for 2020. Phase I report: recommendations for the framework and format of Healthy People 2020. Section IV. Advisory Committee findings and recommendations. Available at: http://www.healthypeople.gov/hp2020/advisory/PhaseI/sec4. htm\#_Toc211942917. Accessed 3/6/14.

5. Gamble VN. Without health and long life all else fails. In: Braithwaite RL, Taylor SE, Treadwell HM, editors. Health issues in the black community. Hoboken: Wiley; 2009.

6. U.S. Department of Health and Human Services. Report of the secretary's task force on Black \& Minority Health. Vol. I. Executive Summary., 1985: Washington, DC.

7. Institute of Medicine. How far have we come in reducing health disparities? Progress since 2000: Workshop summary. Washington, DC: The National Academies Press; 2012.

8. US Department of Health and Human Services. Office of Disease Prevention and Health Promotion., in Healthy People. Understanding and improving health 2000. Washington, DC: U.S. Government Printing Office; 2010.

9. Sondik EJ. Progress toward the healthy people 2010 goals and objectives. Annu Rev Public Health. 2010;31:271-81. 4 p folliwng 281.

10. Smedley B, Stith A, Nelson A. Unequal treatment: confronting racial and ethnic disparities in health care. Washington: National Academies Press; 2003.

11. U.S. Department of Health and Human Services. Overview of the uninsured in the United States: a summary of the 2011 Current Population Survey. 2011; Available from: http://aspe.hhs.gov/ health/reports/2011/cpshealthins2011/ib.shtml.

12. Henry J. Kaiser Family Foundation. Health reform and communities of color: implications for racial and ethnic health disparities. Report No. 8016-02. 2010.

13. Reschovsky JD, O'Malley AS. Do primary care physicians treating minority patients report problems delivering high-quality care? Health Aff (Millwood). 2008;27(3):w222-31.
14. Gaskin DJ, Hadley J. Population characteristics of markets of safety-net and non-safety-net hospitals. J Urban Health. 1999;76(3):351-70.

15. Andrulis, D.P., Patient Protection and Affordable Care Act of 2010: advancing health equity for racially and ethnically diverse populations 2010: Joint Center for Political and Economic Studies.

16. McDonough JE. Health system reform in the United States. Int J Health Policy Manag. 2014;2(1):5-8.

17. RWJF. Disparities in healthcare persist. Available from: http:// www.rwjf.org/content/dam/farm/reports/issue_briefs/2012/ rwjf402390/subassets/rwjf402390 3.

18. Patient Protection and Affordable Care Act. Public Law 111-148. Title IV, x4207, USC HR, 2010. Volume 3590

19. Garfield, R., et al. The coverage gap: uninsured poor adults in states that do not expand medicaid - an update. 2014; Available from: $\mathrm{http} / / \mathrm{kff}$.org/health-reform/issue-brief/the-coverage-gap-uninsured-poor-adults-in-states-that-do-not-expand-medicaid-anupdate/

20. Preston CM, Alexander M. Prevention in the United States Affordable Care Act. J Prev Med Public Health. 2010;43(6):455-8.

21. McGlynn EA et al. The quality of health care delivered to adults in the United States. N Engl J Med. 2003;348(26):2635-45.

22. Rittenhouse DR, Shortell SM, Fisher ES. Primary care and accountable care - two essential elements of delivery-system reform. N Engl J Med. 2009;361(24):2301-3.

23. Dorsey, R., et al., Implementing health reform: improved data collection and the monitoring of health disparities. Annu Rev Public Health, 2013

24. Institute of Medicine. Race, ethnicity and language data: standardization for healthcare quality improvement. Washington, DC: National Academies Press; 2009.

25. Weinick RM, Flaherty K, Bristol S. Creating equity reports: a guide for hospitals. Boston: Disparities Solutions Center and Robert Wood Johnson Foundation; 2008.

26. Green AR et al. Leveraging quality improvement to achieve equity in health care. Jt Comm J Qual Patient Saf. 2010;36(10):435-42.

27. Percac-Lima $\mathrm{S}$ et al. A culturally tailored navigator program for colorectal cancer screening in a community health center: a randomized, controlled trial. J Gen Intern Med. 2009;24(2):211-7.

28. Green AR et al. Barriers to screening colonoscopy for low-income Latino and white patients in an urban community health center. J Gen Intern Med. 2008;23(6):834-40.

29. Weinick RM, Hasnain-Wynia R. Quality improvement efforts under health reform: how to ensure that they help reduce disparitiesnot increase them. Health Aff (Millwood). 2011;30(10):1837-43.

30. Karve $\mathrm{AM}$ et al. Potential unintended financial consequences of pay-for-performance on the quality of care for minority patients. Am Heart J. 2008;155(3):571-6.

31. Weinick RM et al. Hospital executives' perspectives on pay-forperformance and racial/ethnic disparities in care. Med Care Res Rev. 2010;67(5):574-89.

32. Epstein AM, Lee TH, Hamel MB. Paying physicians for highquality care. N Engl J Med. 2004;350(4):406-10.

33. Chien AT et al. Pay for performance, public reporting, and racial disparities in health care: how are programs being designed? Med Care Res Rev. 2007;64(5 Suppl):283S-304S.

34. Hayrinen K, Saranto K, Nykanen P. Definition, structure, content, use and impacts of electronic health records: a review of the research literature. Int J Med Inform. 2008;77(5):291-304.

35. Fiscella K. Health care reform and equity: promise, pitfalls, and prescriptions. Ann Fam Med. 2011;9(1):78-84.

36. Gibbons, M.C., Use of health information technology among racial and ethnic underserved communities. Perspectives in Health Information Management/AHIMA, American Health Information Management Association, 2011. 8(Winter). 
37. Ketcham JD et al. Physician clinical information technology and health care disparities. Med Care Res Rev. 2009;66(6):658-81.

38. Berwick DM. A user's manual for the IOM's 'Quality Chasm' report. Health Aff (Millwood). 2002;21(3):80-90.

39. America, I.o.M.C.o.Q.o.H.C.i., Crossing the quality chasm: a new health system for the 21st century 2001: National Academies Press.

40. Millery M, Kukafka R. Health information technology and quality of health care: strategies for reducing disparities in underresourced settings. Med Care Res Rev. 2010;67(5 Suppl):268S-98S.

41. Chaudhry B et al. Systematic review: impact of health information technology on quality, efficiency, and costs of medical care. Ann Intern Med. 2006;144(10):742-52.

42. Misono AS. Healthcare information technology interventions to improve cardiovascular and diabetes medication adherence. Am J Manag Care. 2010;16(12 Suppl HIT):SP82-92.

43. Weinstock RS et al. Glycemic control and health disparities in older ethnically diverse underserved adults with diabetes: fiveyear results from the Informatics for Diabetes Education and Telemedicine (IDEATel) study. Diabetes Care. 2011;34(2): 274-9.

44. Ngo-Metzger Q et al. Improving communication between patients and providers using health information technology and other quality improvement strategies: focus on low-income children. Med Care Res Rev. 2010;67(5 Suppl):246S-67S.
45. Ngo-Metzger Q et al. Improving communication between patients and providers using health information technology and other quality improvement strategies: focus on Asian Americans. Med Care Res Rev. 2010;67(5 Suppl):231S-45S.

46. Gibbons MC, Casale CR. Reducing disparities in health care quality: the role of health IT in underresourced settings. Med Care Res Rev. 2010;67(5 Suppl):155S-62S.

47. Croskerry P. Achieving quality in clinical decision making: cognitive strategies and detection of bias. Acad Emerg Med. 2002;9(11): 1184-204.

48. Fangmeier J, Eller P, Udow-Phillips M. Affordable care act funding: an analysis of grant programs under health care reformFY2010-FY2013. Ann Arbor: Center for Healthcare Research \& Transformation; 2013.

49. Redhead CS. Appropriations and fund transfers in the patient protection and affordable care act (ACA). Washington, DC: Congressional Research Service; 2013.

50. LaVeist T, Gaskin D, Richard P. The economic burden of health inequalities in the United States. Washington, DC: Joint Center for Political and Economic Studies; 2009.

51. Davis MM, Walter JK. Equality-in-quality in the era of the affordable care act. JAMA. 2011;306(8):872-3.

52. Kohn L, Corrigan J, Donaldson M. To err is human: building a safer health system. Washington, DC: National Academies Press; 2000. 